\title{
ESTUDO DE ADSORÇÃO EM LEITO FIXO DE CORANTES ANIÔNICOS EM ARGILA BENTONITA APÓS TRATAMENTOS TÉRMICO E ÁCIDO
}

\author{
H. C. O. BRUNO ${ }^{1}$, F. R. $\operatorname{SANTOS}^{1}$ e L. Z. MELGAR ${ }^{1}$ \\ ${ }^{1}$ Universidade Federal de São João del Rei, Departamento de Engenharia Química e \\ Estatística \\ E-mail para contato: heloisacarolinabruno@outlook.com
}

\begin{abstract}
RESUMO - O trabalho realizado consiste em modificar a estrutura da argila bentonita, através dos tratamentos ácido e térmico, a fim de melhorar a sua capacidade adsortiva para corantes aniônicos. Assim, foram feitos estudos em modelos matemáticos teóricos de Clark, Yan e Thomas, cálculo da ZTM e da capacidade adsortiva dinâmica. Desse modo, obteve-se, para o sistema de adsorção Alaranjado de Metila em argila bentonita tratada termicamente, o modelo de Clark melhor relacionado, ZTM igual a 3,5 cm e capacidade dinâmica da coluna igual a $8,9 \mathrm{mg} \mathrm{g}^{-1}$. Já para o conjunto Vermelho Congo em argila bentonita tratada química e termicamente, teve-se como resultado o modelo de Yan com melhor correlação, ZTM igual a $0,6 \mathrm{~cm}$ e capacidade de $27,7 \mathrm{mg} \mathrm{g}^{-1}$.
\end{abstract}

\section{INTRODUÇÃO}

Em tratamento de águas, destacam-se as argilas bentonitas do tipo montmorilonita, como adsorventes, pela eficiência na remoção de corantes básicos, ácidos e reativos, alta capacidade adsortiva, resistência a grandes variações de $\mathrm{pH}$, estabilidade química, possibilidade de regeneração e recuperação, de acordo com Duarte-Neto, et al. (2014). Contudo, em alguns casos, é necessário que essas argilas sejam submetidas a tratamentos para melhorarem suas propriedades adsortivas, em especial na remoção de corantes aniônicos.

Segundo Teixeira-Neto e Teixeira-Neto (2009), o tratamento químico com ácidos inorgânicos é utilizado para purificar as argilas esmectíticas, eliminando algumas impurezas, como por exemplo os carbonatos, substituir o cálcio e outros cátions intercalados por cátions hidroxônio $\left(\mathrm{H}_{3} \mathrm{O}^{+}\right)$; e dissociar, nas folhas tetraédricas das camadas, alguns cátions como $\mathrm{Mg}^{2+}, \mathrm{Al}^{3+}, \mathrm{Fe}^{3+}$ ou $\mathrm{Fe}^{2+}$. No tratamento térmico, por sua vez, basicamente ocorrem dois fenômenos, conforme Patricio (2013): a desidratação, sem alteração estrutural, e a desidroxilação, no qual ocorrem alterações na estrutura do argilomineral.

Os tratamentos, além de favorecerem o fenômeno de adsorção, também viabilizam a utilização das argilas bentonitas em colunas de leito fixo, uma vez que impedem o inchamento dessas argilas dentro da coluna. Portanto, o presente trabalho tem como objetivo fazer um estudo de adsorção de corantes aniônicos na argila bentonita, em leito fixo, para dois sistemas: Alaranja de Metila em Argila Bentonita Tratada Termicamente (AM-AT), e Vermelho Congo em Argila Bentonita Tratada Química e Termicamente (VC-AAT). Assim, 
foram analisados os modelos matemáticos teóricos de Clark, Yan e Thomas e foram observados os parâmetros da coluna como a ZTM e Capacidade adsortiva dinâmica que forneceram informações importantes do processo.

\section{PARTE EXPERIMENTAL}

\subsection{Materiais}

No desenvolvimento desta pesquisa, a argila utilizada foi do tipo Bentonita sódica natural proveniente da cidade de Uruguaiana - RS, cedida pela empresa ALIANÇA LATINA INDÚSTRIA E COMÉRCIO LTDA. Como adsorvatos foram utilizados o corante diazo aniônico Vermelho Congo (VC) e o corante azo aniônico Alaranjado de Metila (AM), ambos fornecidos pela empresa DINÂMICA QUÍMICA CONTEMPORÂNEA LTDA. Ácido sulfúrico 95-99\% (m/m) de pureza, fornecido pela VETEC Química Fina. Para a realização dos experimentos, foi desenvolvida e construída uma coluna de vidro encamisada com $1 \mathrm{~cm}$ de diâmetro interno.

\subsection{Método}

Caracterização: As amostras foram previamente desagregadas em almofariz e padronizadas em peneira malha 200 mesh $(0,074 \mathrm{~mm})$. O material foi caracterizado por difratometria de raio-X em equipamento Miniflex, modelo Rigaku 300/600+, usando radiação de $\operatorname{CuK} \alpha\left(\lambda=1,5418 \AA\right.$ ). Corrente de $15 \mathrm{~mA}$ e tensão de $40 \mathrm{kV}$, com varredura de $5^{\circ} \mathrm{a} 60^{\circ}(2 \Theta)$ e velocidade de $1^{\circ} \mathrm{min}^{-1}$.

Tratamento Térmico: A argila in natura foi submetida ao processo de calcinação em Forno Mufla SP Labor, modelo SP-1200, a $500{ }^{\circ} \mathrm{C}$ pelo período de 24 horas.

Tratamento Ácido e Térmico: A argila in natura, padronizada em peneira malha 200 mesh, foi suspensa em água destilada e, após esse processo, foi adicionado ácido sulfúrico, resultando em uma solução $4 \mathrm{~mol} \mathrm{~L}^{-1}$, mantida sob agitação constante, durante um período de 12 horas, à temperatura de $90^{\circ} \mathrm{C}$. O material foi filtrado, utilizando bomba à vácuo New Pump e submetido a 3 lavagens sucessivas com água destilada. Após esse processo, a argila foi suspensa em água e ajustou-se o pH para 6, com solução de hidróxido de sódio. O material foi lavado, mais uma vez, e seco em Estufa Sterilifer, modelo SX 1.1 DTME, à $60^{\circ} \mathrm{C}$. Posteriormente, foi triturado e classificado para a obtenção do diâmetro médio de partícula de $0,074 \mathrm{~mm}$ (peneira malha 200 mesh). Em seguida, realizou-se o tratamento térmico de forma análoga ao descrito anteriormente.

Testes de Adsorção: Para avaliar os efeitos dos tratamentos na argila bentonita, foram realizados ensaios em bateladas, no qual foi calculado a porcentagem de remoção dos corantes em cada sistema, AM-AT e VC-AAT. Para esses sistemas, foram realizados os ensaios com as seguintes especificações: $100 \mathrm{mg}$ de adsorvente foram adicionados a $50 \mathrm{~mL}$ de solução de corante com concentração de $50 \mathrm{mg} \mathrm{L}^{-1}$ e mantidas em contato durante 1 hora, sob agitação constante, para formação de suspensão homogênea. As respectivas absorbâncias foram determinadas utilizando o espectrofotômetro de UV-VIS Micronal, modelo AJX-1600 Spectrophotometer, comprimento de onda de $497 \mathrm{~nm}$ para o VC e $468 \mathrm{~nm}$ para o AM, empregando-se uma cubeta de quartzo de caminho óptico de $1,0 \mathrm{~cm}$. 
Leito Fixo e Curva de Ruptura: Utilizou-se uma coluna de vidro encamisada de $1 \mathrm{~cm}$ de diâmetro interno, preenchida com chumaço de algodão e esferas de vidro para fixação do leito. Os experimentos foram realizados em fluxo ascendente, à temperatura ambiente de 26 ${ }^{\circ} \mathrm{C}$. As concentrações de saída foram monitoradas utilizando a espectrofotometria de UV-VIS. Na Tabela 1, estão presentes as condições de operação da coluna para os sistemas AM-AT e VC-AAT.

Tabela 1 - Condições de operação da coluna para os sistemas AM-AT e VC-AAT.

\begin{tabular}{|c|c|c|}
\hline Parâmetros & AM-AT & VC-AAT \\
\hline \hline Diâmetro $(\mathrm{cm})$ & 1,00 & 1,00 \\
\hline Altura do leito $(\mathrm{cm})$ & 4,10 & 0,80 \\
\hline Vazão $\left(\mathrm{ml} \mathrm{min}^{-1}\right)$ & 4,50 & 4,00 \\
\hline Concentração $\left(\mathrm{mg} \mathrm{L}^{-1}\right)$ & 15,00 & 50,00 \\
\hline Granulometria $(\mathrm{mm})$ & $0,354-0,595$ & $0,354-0,595$ \\
\hline
\end{tabular}

\section{RESULTADO E DISCUSSÃO}

\subsection{Caracterização}

Através da análise da Figura 1, no difratograma de raio X da argila in natura, verificouse um pico de elevada intensidade em torno de $2 \theta=7,04^{\circ}$, relativo à distância interplanar basal do argilomineral montmorilonita na ordem de 12,55 $\AA$. Após o tratamento térmico, ocorreu um deslocamento do pico de $2 \theta=7,04^{\circ}$ para $2 \theta=7,88^{\circ}$, indicando uma redução do espaçamento basal (d001) de 12,55 $\AA$ para 11,20 ̊, distâncias obtidas pela lei de Bragg. Isso é observado porque, à $500^{\circ} \mathrm{C}$, a estrutura da argila se colapsa, havendo desidratação e desidroxilação devido à eliminação de águas de hidratação de cátions interlamelares (NETO et al., 2012 e ARAUJO et al., 2012). Na amostra da argila tratada em meio ácido e tratamento térmico, constatou-se o deslocamento do pico de $2 \theta=7,04^{\circ}$ para $2 \theta=8,94^{\circ}$, o que expressou uma maior redução do espaçamento basal, de 12,55 ̊ para 10,98 $\AA$, pela lei de Bragg. Isso aconteceu porque, além dos efeitos gerados pela calcinação da argila já mencionados, ocorreram eliminações de muitas impurezas minerais e dissolução parcial das lamelas cristalinas, provocadas pelo tratamento da argila com ácido inorgânico (TEIXEIRA-NETO E TEIXEIRA-NETO, 2009).

Figura 1 - Difratograma de raios $\mathrm{X}$ das amostras de argila in natura, calcinada e trada em meio ácida com calcinação.

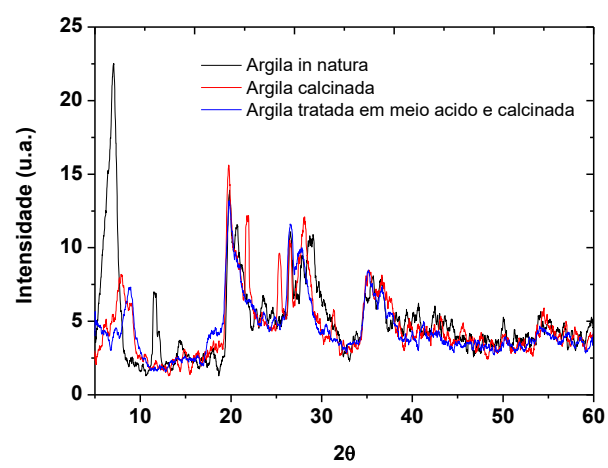




\subsection{Teste de Adsorção}

Observando a Figura 2, notou-se que os tratamentos na argila bentonita apresentaram resultados promissores, visto que ocorreu um aumento da porcentagem de remoção. Durante os testes não foi observado a adsorção do Alaranjado de Metila em Argila Bentonita tratada em Meio Ácido. O AM tem a sua solubilidade reduzida em meio ácido, ocorrendo a precipitação do mesmo. Além disso, o tratamento ácido da argila aumenta as cargas negativas superficiais (Selvam et al., 2008) que, por sua vez, provocam a repulsão eletrostática com o corante aniônico AM. Contudo o tratamento térmico se mostrou efetivo.

A combinação dos tratamentos químico e térmico foi benéfico, permitindo uma porcentagem de remoção do Vermelho Congo de $80 \%$. Isso foi possível porque ocorrem modificações estruturais nas argilas quando submetidas a meios com ácidos inorgânicos tais como: áreas superficiais maiores, maior porosidade e boa estabilidade térmica, segundo Teixeira-Neto e Teixeira-Neto (2009). Somado a isso, o tratamento térmico, contribuiu para evitar o inchamento da argila na coluna, devido ao colapso de sua estrutura, provocado pela eliminação de águas de hidratação de cátions interlamelares, como descrito no trabalho de Neto et al., (2012).

Figura 2 - Porcentagem de remoção dos corantes VC e AM em argila in Natura e nos sistemas VC-AAT e AM-AT.

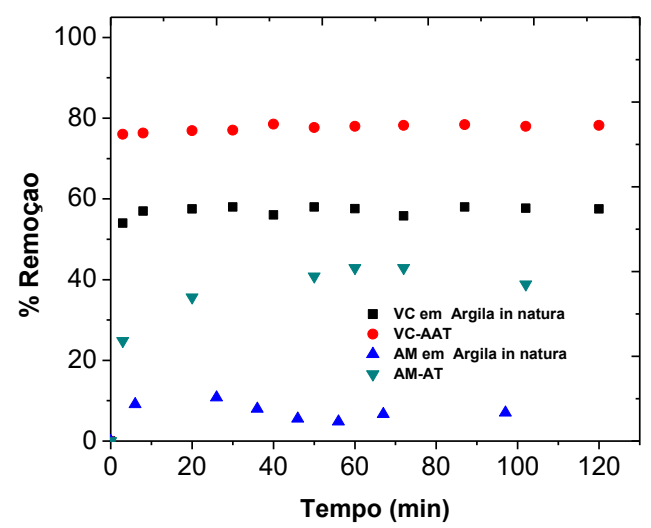

\subsection{Leito fixo e Curva de ruptura}

Os dados coletados em escala de laboratório servem como base para o design de colunas em grande escala de leitos-fixos adsorvedores. Para isso, utiliza-se modelos matemáticos a fim de se obter de parâmetros importantes que auxiliarão nessa tarefa. Dentre eles, destacam-se o modelo de Thomas (Nascimento et al., 2014), Clark (Canteli, 2013) e Yan (Canteli, 2013).

A Figura 3 ilustra os dados experimentais obtidos para o sistema de adsorção AM-AT e VC-AAT, com os respectivos modelos teóricos. 
Figura 3 - Curva de ruptura da adsorção do sistema AM-AT, com $15 \mathrm{mg} \mathrm{L}^{-1}$ de concentração do corante, vazão de $4,5 \mathrm{~mL} \mathrm{~min}^{-1}$ e altura do leito $4,1 \mathrm{~cm}$ e Curva de ruptura da adsorção do sistema VC-AAT, com $50 \mathrm{mg} \mathrm{L}^{-1}$ de concentração do corante, vazão de $4 \mathrm{~mL}$ $\min ^{-1}$ e altura do leito $0,8 \mathrm{~cm}$.
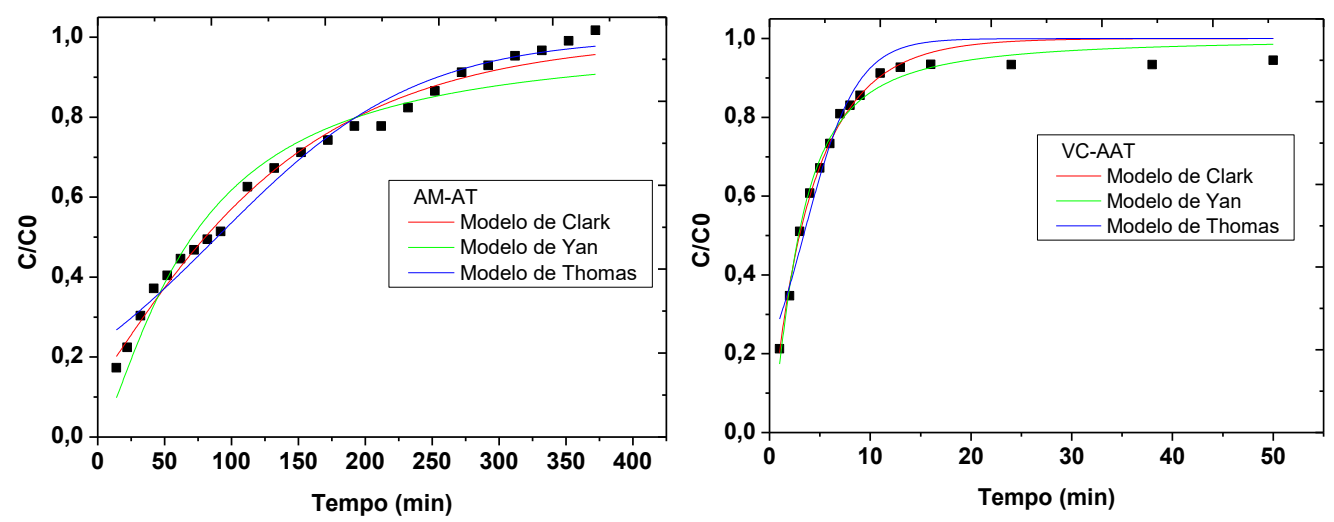

Pode-se observar que o sistema VC-AAT mostrou-se mais próximo da idealidade. Quanto mais aberto é o formato da curva, maior é a resistência à transferência de massa, ao passe que a curva se torna mais fechada à medida que a resistência à transferência de massa diminui. Quanto menor esta região, maior o tempo de serviço da coluna durante o estágio de alimentação e mais completa é a dessorção do adsorvato (Nascimento et al., 2014). A Tabela 2 apresenta os parâmetros encontrados conforme cada modelo matemático teórico aplicado. Para o processo de adsorção do conjunto AM-AT o melhor modelo correlacionado foi o de Clark, enquanto que para o conjunto VC-AAT o melhor modelo correlacionado foi o de Yan.

A análise da ZTM e da Capacidade dinâmica da coluna (U), também são características importantes nesse estudo. Dessa forma a ZTM foi calculada de acordo segundo BARBOSA et al., (2014). A Tabela 2 apresenta os valores encontrados para cada conjunto.

Tabela 2 - Parâmetros dos modelos matemáticos de adsorção e propriedades físicas de operação da coluna para o conjunto AM-AT e VC-AAT.

\begin{tabular}{|c|c|c|c|}
\hline Modelos & Parâmetros dos modelos & AM-AT & VC-AAT \\
\hline \hline \multirow{3}{*}{ Thomas } & $\mathrm{q}_{0}\left(\mathrm{mg} \mathrm{g}^{-1}\right)$ & 1,513 & 10,567 \\
\cline { 2 - 4 } & $\mathrm{K}_{\mathrm{T}} \cdot 10^{5}\left(\mathrm{~mL} \mathrm{mg}^{-1} \mathrm{~min}^{-1}\right)$ & 9,355 & 0,6 \\
\cline { 2 - 4 } & $\mathrm{R}^{2}$ & 0,978 & 0,975 \\
\hline \multirow{3}{*}{ Yan } & $\mathrm{a}$ & 1,259 & 0,786 \\
\cline { 2 - 4 } & $\mathrm{b} \cdot 10^{-3}$ & 0,302 & 0,116 \\
\cline { 2 - 4 } & $\mathrm{R}^{2}$ & 0,972 & 0,985 \\
\hline \multirow{4}{*}{ lark } & $\mathrm{a}$ & 0,501 & 0,034 \\
\cline { 2 - 4 } & $\mathrm{r} \cdot 10^{4}$ & 107,201 & 12,567 \\
\cline { 2 - 4 } & $\mathrm{n}$ & 1,267 & 0,078 \\
\cline { 2 - 4 } & $\mathrm{R}^{2}$ & 0,988 & 0,967 \\
\hline \hline & Propriedades da coluna & AM-AT & VC-AAT \\
\hline & $\mathrm{ZTM}(\mathrm{cm})$ & 3,5 & 0,6 \\
\cline { 2 - 4 } & $\mathrm{U}\left(\mathrm{mg} \mathrm{g}^{-1}\right)$ & 8,9 & 27,7 \\
\hline
\end{tabular}




\section{CONCLUSÃO}

De acordo com os dados analisados, inferiu-se que a argila bentonita tratadas apresentou uma capacidade adsortiva promissores quando empregada em leito fixo para corantes aniônicos. Isso ocorreu devido à eficiência dos tratamentos térmico e ácido que minimizaram a repulsão eletrostática entre os corantes e a superfície da argila, ambos de natureza negativa. Dessa forma obteve-se, para o sistema de adsorção AM-AT, o modelo de Clark melhor relacionado, ZTM igual a $3,5 \mathrm{~cm}$ e Capacidade dinâmica da coluna igual a $8,9 \mathrm{mg} \mathrm{g}^{-1}$. Já para o conjunto VC-AAT, teve-se como resultado o modelo de Yan com melhor correlação, ZTM igual a $0,6 \mathrm{~cm}$ e capacidade de $27,7 \mathrm{mg} \mathrm{g}^{-1}$.

\section{REFERENCIAS BIBLIOGRÁFICAS}

BARBOSA, E. M. C. Materiais mistos nanoestruturados baseados em argila bentonita e cobalto coloidal. 2009. 56 f. Dissertação (Programa de Pós-Graduação em Química) Universidade Estadual do Centro-Oeste, Paraná. 2009.

CANTELI, A. M. D. Recuperação do aroma de café, benzaldeído, em coluna de adsorção utilizando carvão ativado. 2013. 129 f. Dissertação (Pós-graduação em Engenharia de Alimentos) - Universidade Federal do Paraná, Curitiba. 2013.

DUARTE-NETO, J. F.; CARTAXO, J. M.; NEVES, G. A.; MENEZES, R.R. Processos de adsorção de corantes em argilas esmectíticas: uma revisão. Revista Eletrônica de Materiais e Processos - Departamento de Engenharia de Materiais da Universidade Federal de Campina Grande, Campina Grande, n. 1, p. 51-59, vol. 9. 2014.

NASCIMENTO, R. F.; LIMA, A. C. A; VIDAL, C. B.; MELO, D. Q.; RAULINO, G. S. C. Adsorção: Aspectos teóricos e aplicações ambientais. Fortaleza: Imprensa Universitária. 2014. 256p.

NETO, A. F. N.; VIEIRA, M. G. A.; DA SILVA, M. G. C. Caracterização térmica de argilas bentoníticas destinadas à remoção de metais. TTT 2012 - VI Conferência Brasileira sobre Temas de Tratamento Térmico. - Faculdade de Engenharia Química Unicamp, Atibaia, SP. 2012.

PATRICIO, J. S. Caracterização de argilas naturais e ativadas aplicadas na clarificação de óleo de soja. 2013. 83 f. Dissertação (Programa de Pós-Graduação em Ciência e Engenharia de Materiais) - Universidade Federal de Santa Catarina, Florianópolis. 2013.

QUADROS, S. S. Tratamento e reutilização de efluentes têxteis gerados nos tingimentos de tecidos de algodão. 2005. 110 f. Dissertação (Programa de Pós-Graduação em Química) - Universidade Regional de Blumenau, Blumenau. 2005.

SELVAM, P.P.; PREETHI, S.; BASAKARALINGAM, P.; Removal of rhodamine B from aqueous solution by adsorption onto sodium montmorillonite. Elsevier (Journal of Hazardous Materials) - Department of Chemical Engineering A. C. College of Technology, Tamilnadu, India, n. 155, p. 39-44. 2008.

TEIXEIRA-NETO, E.; TEIXEIRA-NETO, A. Modificação química de argilas: desafios científicos e tecnológicos para obtenção de novos produtos com maior valor agregado. Química Nova - Centro de Ciências Naturais e Humanas da Universidade Federal do ABC, São Paulo, n. 3, p. 809-817, vol. 32. 2009. 